\title{
Prevalence of Overweight and Obesity among Chinese Adults: Role of Adiposity Indicators and Age
}

\author{
Weili Xu ${ }^{a, b}$ Hua Zhang ${ }^{c}$ Stephanie Paillard-Borg ${ }^{d}$ Hong Zhu $^{a}$ \\ Xiuying $\mathrm{Qi}^{\mathrm{a}}$ Debora Rizzuto ${ }^{\mathrm{b}}$ \\ a Department of Epidemiology and Biostatistics, School of Public Health, Tianjin Medical \\ University, Tianjin, China; ${ }^{b}$ Aging Research Center (ARC), Department Neurobiology, Health \\ Care Sciences and Society, Karolinska Institutet and Stockholm University, Stockholm, \\ Sweden; ' School of Nursing, Tianjin Medical University, Tianjin, China; ${ }^{d}$ Red Cross University \\ College, Stockholm, Sweden
}

\section{Key Words}

Overweight · Obesity · Body mass index $\cdot$ Waist circumference $\cdot$ Waist-to-hip ratio

\begin{abstract}
Objectives: The role of different body fat indicators and age in assessing the prevalence of obesity is unclear. We aimed to examine to what extent different body fat indicators including BMI, waist circumference (WC) and waist-to-hip ratio (WHR) affect the prevalence of overweight and obesity among Chinese adults taking age into account. Methods: This populationbased cross-sectional study included a random sample of 7,603 adults aged 20-79 years across entire Tianjin, China. BMI, WC, and WHR were used to define overweight and obesity following standard criteria. Prevalence rates were calculated and standardized using local age- and gender-specific census data. Logistic regression was used in data analysis. Results: Using the combination of BMI, WC, and WHR, the prevalence of overweight and obesity was $69.8 \%$, and increased with age till the age of 60 and a decline thereafter. The prevalence of overweight assessed by BMI was higher than that assessed by WC and WHR, while the prevalence of obesity defined by BMI was much lower than that defined by WC or WHR. Conclusion: The prevalence of overweight and obesity is about $70 \%$ among Chinese adults. Adiposity indicators and age play an important role in the prevalence of overweight and obesity.
\end{abstract}


Xu et al.: Prevalence of Overweight and Obesity among Chinese Adults: Role of Adiposity Indicators and Age

\section{Introduction}

Despite the enormous efforts to control obesity, the prevalence of overweight and obesity has nearly doubled in the past 20 years [1]. Obesity has become a global pandemic affecting more than 1.4 billion adults aged 20 and older [1]. A recent report estimated that the number of overweight adults in the world was 2.1 billion in 2013, compared with 857 million in 1980 [2]. Overweight and obesity are the 5th leading risk for global deaths [3]. At least 2.8 million adults die each year as a result of being overweight or obese. In addition, $44 \%$ of the diabetes, $23 \%$ of the ischemic heart disease and $7-41 \%$ of certain cancer burdens are attributable to overweight and obesity [1]. According to the World Health Organization (WHO), obesity in China is a major health concern, with overall rates of obesity below $5 \%$ in the country, but greater than $20 \%$ in some cities [1]. A meta-analysis of nationally representative data estimated that the prevalence of overweight and obesity increased from 16\% in 1992 to $23 \%$ in 2002 [4]. In 2010, the prevalence of overweight and obesity among Chinese adults was $30.6 \%$ and $12.0 \%$, respectively [5].

Several anthropometric indicators of adiposity are frequently used to define overweight and obesity, such as BMI, waist circumference (WC), and waist-to-hip ratio (WHR). Although BMI is correlated with total body fat tissue, it does not take body fat distribution into account and may differ greatly across populations and age [6,7]. WC and WHR measure body fat centralization [8,9], and are considered to be good proxies of visceral fat [10]. However, WC might under- and over-estimate central adiposity in short and tall individuals, respectively [10]. Therefore, different anthropometric indicators for body fat may play an important role in assessing adiposity and affect the prevalence of obesity [11]. So far, only few populationbased studies have shown the prevalence of overweight and obesity using different adiposity indicators in Asian population [12,13].

Aging is associated with considerable changes in body composition. As aging may change total body weight, both men and women usually gain weight until the age of 60 and begin to lose weight thereafter. Weight loss in later life occurs in part because of lean muscle tissue loss [14]. Indeed, the prevalence of obesity increases with age up to 50 or 60 years [15]. The estimation of body fat in the elderly people using BMI could be distorted by muscle mass and bone structure loss, as it does not account for the different ratios of adipose to lean tissue; thus general and central obesity could not be distinguished [16]. Questions remain about the role of different adiposity indicators and age in assessing obesity. In the present study, we aimed: i) to examine whether and to what extent different body fat indicators, such as BMI, WC and WHR, affect the prevalence of overweight and obesity; and ii) to assess the differences in the distribution of overweight and obesity defined by the three indicators taking age into account.

\section{Material and Methods}

\section{Study Participants}

Data were gathered from the project of Diabetes Mellitus in Tianjin (DM-TJ), which was a populationbased cross-sectional study on diabetes carried out in Tianjin, China, in July 2005, as described in detail elsewhere $[17,18]$. In brief, the study population was derived from all inhabitants living in Tianjin through a multiphase stratified cluster sampling method. A three-step randomized sampling procedure was performed: first, two urban districts and one suburb were drawn from the city; second, three communities were selected from each of the three areas; and finally, three neighborhoods were chosen from each community. A total of 18 urban and nine suburb blocks were targeted, and all inhabitants $(\mathrm{N}=7,990)$, who were living in the blocks for more than 5 years and aged 20-79 years, were initially invited to participate in the study. In total, 7,613 $(95 \%)$ individuals underwent a health interview, physical examination, and fasting capillary plasma glucose 
Xu et al.: Prevalence of Overweight and Obesity among Chinese Adults: Role of Adiposity Indicators and Age

test. Of those individuals, 7,603 were left for the current analyses after excluding 10 with missing information on BMI or WC. The ethics committee at the Tianjin Medical University approved the project, and informed consensus was obtained for all the participants.

\section{Data Collection}

Data on age, sex, education, lifestyle, health status, and family history of chronic disease were collected from participants at the interview. Education was calculated by the maximum years of formal schooling and dichotomized ( $>9$ vs. $\leq 9$ years). Cigarette smoking (current smokers vs. former or non-smokers) and alcohol consumption (drinkers vs. former or non-drinkers) were also dichotomized. Physical inactivity was defined as physical activity less than two times per week. Using a mercury sphygmomanometer, seated blood pressure was measured twice on the right brachial artery after a 5-min rest. The mean value of the two readings was used as the final measure. Hypertension was defined as systolic blood pressure $\geq 140 \mathrm{~mm} \mathrm{Hg}$ and/or diastolic blood pressure $\geq 90 \mathrm{~mm} \mathrm{Hg}$, having a medical history of hypertension, or the use of antihypertensive medications. Fasting capillary blood samples were taken from all participants, and capillary plasma glucose was measured by OneTouch ${ }^{\circledR}$ ULTRA 2 meter (LifeScan Inc., Wayne, PA, USA). After the screening test, subjects with capillary plasma glucose level $\geq 5.4 \mathrm{mmol} / \mathrm{l}$ underwent a fasting plasma glucose (FPG) test and a postprandial 2-hour plasma glucose test after eating a steamed bread meal containing carbohydrates equivalent to $75 \mathrm{~g}$ of glucose. Type 2 diabetes mellitus (T2DM) was assessed as having previous diagnosed diabetes, FPG $\geq 7.0 \mathrm{mmol} / \mathrm{l}$, or postprandial 2-hour plasma glucose $\geq 11.1 \mathrm{mmol} / \mathrm{l}$ [19].

\section{Adiposity Indicators and Assessments}

Height and weight were measured in light clothes without shoes and recorded to the nearest $0.1 \mathrm{~cm}$ or $100 \mathrm{~g}$. BMI was calculated as weight in kilograms divided by the square of height in meters. According to the recommended criteria for the Chinese people, underweight (BMI $<18.5 \mathrm{~kg} / \mathrm{m}^{2}$ ), normal weight (BMI 18.5$23.9 \mathrm{~kg} / \mathrm{m}^{2}$ ), overweight (BMI $24.0-27.9 \mathrm{~kg} / \mathrm{m}^{2}$ ), and obesity (BMI $\geq 28 \mathrm{~kg} / \mathrm{m}^{2}$ ) were assessed [20]. WC was measured at the midway between the lower rib margin and the anterior superior iliac spine. Hip circumference (HC) was measured over the maximum of the buttocks. For both measurements a flexible tape was used, and data were recorded to the nearest $0.1 \mathrm{~cm}$. In men, a $W C$ of $<85 \mathrm{~cm}$ was defined as normal weight, a WC of $85-94.9 \mathrm{~cm}$ as overweight, and a WC $\geq 95 \mathrm{~cm}$ as obesity; the respective values for women were $<80$ $\mathrm{cm}, 80-89.9 \mathrm{~cm}$, and $\geq 90 \mathrm{~cm}$ [20]. Waist-to-hip ratios (WHR) were calculated as WC divided by HC. WHR was considered as normal, overweight and obese if WHR was $<0.90,0.90-0.99$ and $\geq 1.0$ in men or $<0.80$, $0.80-0.84$ and $\geq 0.85$ in women, respectively [20].

Total overweight and obesity was defined as BMI $\geq 24 \mathrm{~kg} / \mathrm{m}^{2}$, WC $\geq 85 \mathrm{~cm}$ for men and $\geq 80 \mathrm{~cm}$ for women, or WHR $\geq 0.9$ for men and $\geq 0.8$ for women, according to the Working Group on Obesity in China [20].

\section{Statistical Analysis}

The sex-specific characteristics of participants were compared using chi square tests for categorical variables and t-test for continuous variables. The prevalence rates were calculated as the number of people with overweight and/or obesity divided by number of participants. Standardized estimates of prevalence were calculated by the direct method based on the age- and sex-specific structure in the population aged 20-79 years in the Tianjin city based on the Annual Statistic Report, Tianjin, 2005. Partial correlation analyses were performed to quantify the independent associations between the three anthropometric indices. Logistic regression analyses were performed to estimate the odds ratios (ORs) and $95 \%$ confidence interval (CIs) for the cross-sectional association of overweight and/or obesity with age, sex, education, smoking, alcohol drinking, physical inactivity, hypertension, and diabetes. Overweight and obesity were used as separate or combined outcomes, and normal-weight participants were used as a reference group in the logistic regression models, participants with underweight were excluded from this analysis. All statistical analyses were performed using IBM SPSS Statistics 20.0 (IBM Corp, New York, NY, USA) and Stata 14 (StataCorp, College Station, TX, USA).

\section{Results}

Of all participants, 3,963 (52.1\%) were women, and the mean \pm SD age was $48.1 \pm 13.9$ years for men and $47.8 \pm 13.9$ for women. Compared to women, men tend to have higher BMI, WC, and HC (all p < 0.05), higher numbers of smokers and alcohol drinkers, more years of 
Xu et al.: Prevalence of Overweight and Obesity among Chinese Adults: Role of Adiposity Indicators and Age

Table 1. Characteristics of the study participants by $\operatorname{sex}(n=7,603)^{a}$

\begin{tabular}{|c|c|c|c|c|}
\hline Characteristics & Men $(n=3,640)$ & Women $(n=3,963)$ & Total $(\mathrm{n}=7,603)$ & $p$ value $^{\dagger}$ \\
\hline Age, years & $48.1 \pm 13.9$ & $47.8 \pm 13.9$ & $48.0 \pm 13.9$ & 0.366 \\
\hline Education* & & & & $<0.001$ \\
\hline$\leq 9$ years & $2,378(65.4)$ & $2,756(69.6)$ & $5,134(67.6)$ & \\
\hline$>9$ years & $1,257(34.6)$ & $1,201(30.4)$ & $2,458(32.4)$ & \\
\hline Cigarette smoking* & $1,978(54.8)$ & $532(13.5)$ & $2,510(33.3)$ & $<0.001$ \\
\hline Alcohol drinking* & $1,907(53.6)$ & $226(5.8)$ & $2,133(28.6)$ & $<0.001$ \\
\hline Physical inactivity* & $2,188(60.5)$ & $2,361(71.6)$ & 4,549 (65.8) & $<0.001$ \\
\hline Hypertension* & $1,235(35.0)$ & $1,275(32.3)$ & $2,510(33.6)$ & 0.013 \\
\hline Diabetes & $331(9.1)$ & $438(11.1)$ & $769(10.1)$ & 0.005 \\
\hline BMI, $\mathrm{kg} / \mathrm{m}^{2}$ & $24.3 \pm 3.2$ & $24.2 \pm 3.6$ & $24.3 \pm 3.4$ & 0.039 \\
\hline $\mathrm{WC}, \mathrm{cm}$ & $86.5 \pm 9.5$ & $76.2 \pm 9.9$ & $81.1 \pm 11.0$ & $<0.001$ \\
\hline $\mathrm{HC}, \mathrm{cm}$ & $96.7 \pm 6.8$ & $94.9 \pm 7.2$ & $95.8 \pm 7.1$ & $<0.001$ \\
\hline
\end{tabular}

aData are $\mathrm{n}(\%)$ or means \pm standard deviation.

*Numbers of participants with missing values: 11 for education, 57 for cigarette smoking, 153 for alcohol drinking, 690 for physical inactivity, 123 for hypertension.

${ }^{\dagger}$ Chi square tests for categorical variables and t test for continuous variables.

Table 2. Correlation coefficient among anthropometric indicators in the total population stratified by age and gender

\begin{tabular}{llll}
\hline & BMI, kg/m $\mathrm{m}^{2}$ & WC, cm & WHR \\
\hline $\begin{array}{l}\text { Total population } \\
\text { BMI }\end{array}$ & 1.000 & & \\
WC & 0.556 & 1.000 & \\
WHR & 0.387 & 0.839 & 1.000 \\
\hline$<60$ years & & & \\
BMI & 1.000 & & \\
WC & 0.556 & 1.000 & \\
WHR & 0.386 & 0.839 & 1.000 \\
\hline$\geq 60$ years & & & \\
BMI & 1.000 & & \\
WC & 0.559 & 1.000 & \\
WHR & 0.389 & 0.839 & \\
\hline Men & & & \\
BMI & 1.000 & & \\
WC & 0.693 & 1.000 & \\
WHR & 0.478 & 0.779 & 1.000 \\
\hline Women & & & \\
BMI & 1.000 & 1.000 & \\
WC & 0.561 & 0.799 & \\
WHR & 0.423 & & \\
\hline
\end{tabular}

formal schooling ( $>9$ years) (all $p<0.001$ ), and higher numbers of hypertension $(\mathrm{p}<0.05)$. However, there were fewer men who were physically inactive $(\mathrm{p}<0.001)$ and had type 2 diabetes $(\mathrm{p}<0.01)$ (table 1$)$.

Table 2 shows the pair-wise correlation between BMI, WC, and WHR in the total population and stratified by age ( $<60$ vs. $\geq 60$ years, because of body weight changes at this age) and sex. The correlation of WC and WHR was high ( $\mathrm{r}=0.839)$, but the correlation of BMI with WC or WHR was rather low $(r=0.556$ or $r=0.387)$ in the total population. 
Xu et al.: Prevalence of Overweight and Obesity among Chinese Adults: Role of Adiposity Indicators and Age

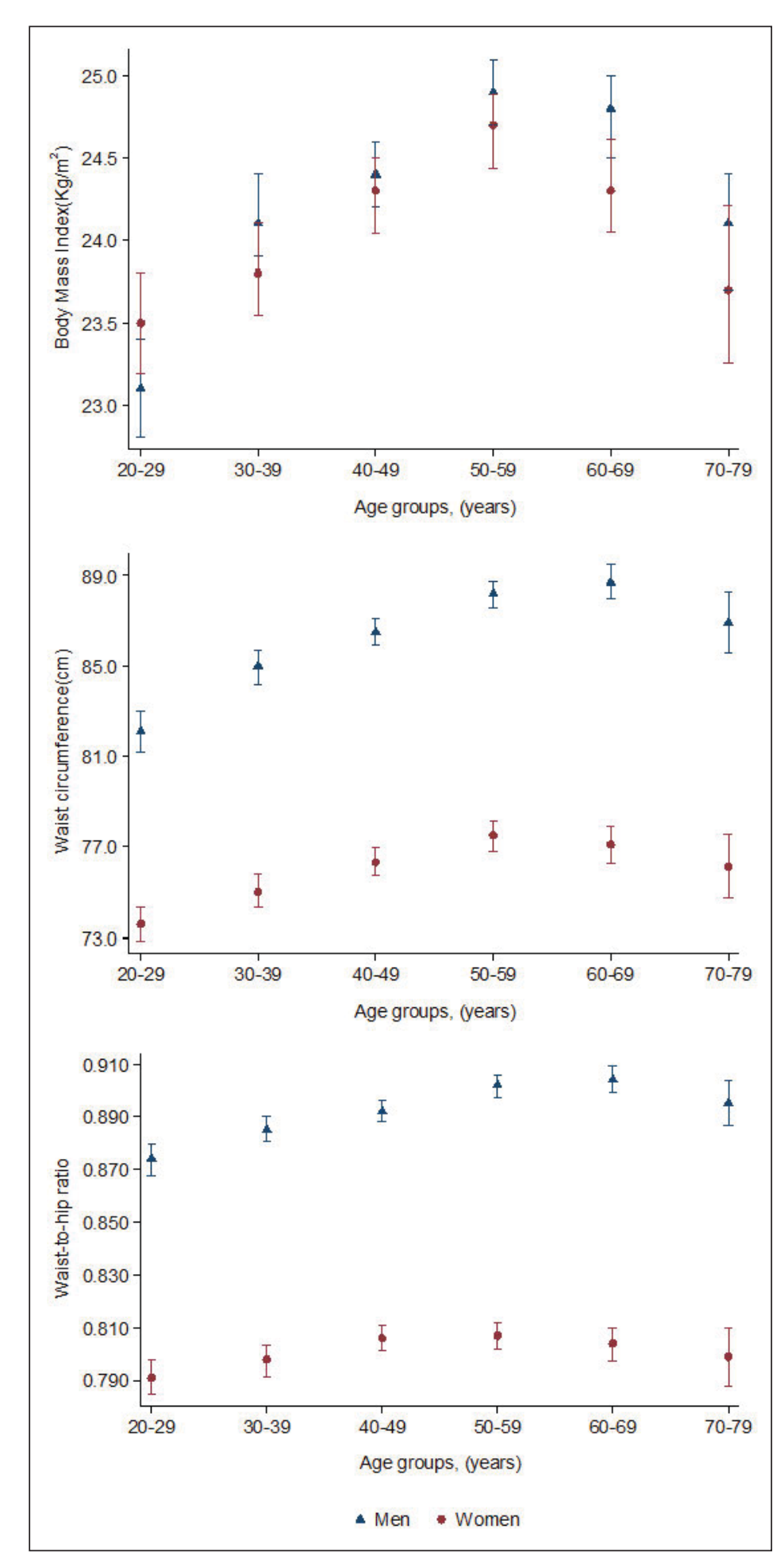

Fig. 1. Mean and $95 \%$ CI of BMI WC, and WHR by age groups in men and women.

Mean BMI, WC, and WHR according to age groups and sex are shown in figure 1. Though the mean of three indicators changed with age in both men and women, but the patterns were different. The mean BMI was higher in women than in men in people aged 20-29 years, but this relation was reversed in people $\geq 30$ years. The changes of both mean WC and WHR with age were parallel, but the age at the changes were different. Mean WC increased with age till 

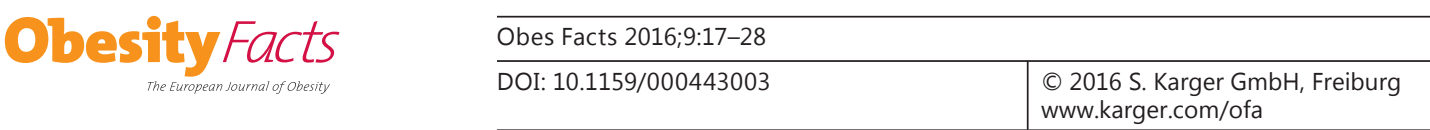

Xu et al.: Prevalence of Overweight and Obesity among Chinese Adults: Role of Adiposity Indicators and Age

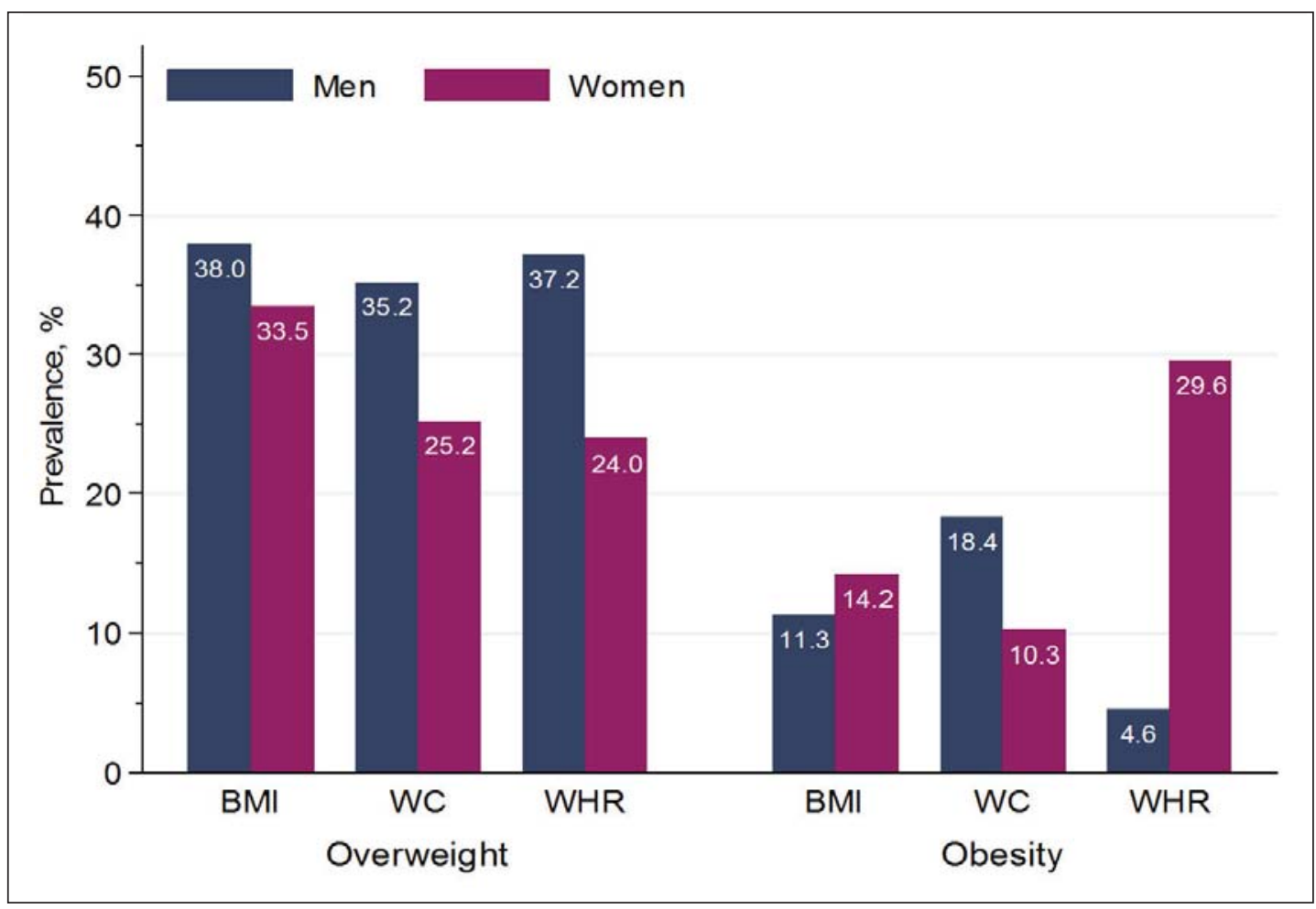

Fig. 2. Standardized prevalence of overweight and obesity according to BMI, WC, and WHR by sex.

the age of 50-59 years while mean WHR tended to increase with age up to the age of 60-69 years; afterwards in both a decline was seen.

In the total population, the standardized prevalence rates for overweight or obesity were $35.7 \%$ or $12.8 \%$ using BMI, $30.0 \%$ or $14.2 \%$ using WC, and $30.3 \%$ or $17.7 \%$ using WHR The prevalence of overweight using any of the three indicators was higher in men than in women (all $\mathrm{p}<0.001$ ). The prevalence of obesity defined by BMI or WHR was higher in women than in men (all $p<0.001$ ), but when obesity was defined by WC, it was higher in men than in women ( $\mathrm{p}<0.001$ ) (fig. 2).

Figure $3 \mathrm{~A}$ presents the prevalence of overweight according to BMI, WC, and WHR separated by age and sex. In both men and women, the prevalence of overweight based on BMI increased with age up to the age of 60 and a decline thereafter, and was generally higher than that based on WC and WHR except for the youngest men (age group 20-29 years) and men $\geq$ 60 years. Compared to women, the prevalence rates of overweight by BMI were closer to those defined by WC and WHR in men. The prevalence of obesity showed a similar pattern across age groups. However, dramatic variations among the three indicators were shown in both men and women. The prevalence of obesity by WC was much higher than that by the other two indicators in men, while in women the prevalence defined by WHR was considerably higher than those defined by BMI and WC in all age groups (fig. 3B).

Using a combination of the three anthropometric indicators, the prevalence of overall high adiposity was $69.8 \%$ (68.5\% in women and $71.2 \%$ in men, $\mathrm{p}=0.013)$, and generally increased with age till the age of 60 and a decline thereafter in the total population (fig. 4). The prevalence was higher in women than in men $<30$ years, but this relation was reversed in people $\geq 30$ years, with highest rates in men aged $50-59$ years. After the age of 60 a decline in overall high adiposity prevalence was seen in both men and women. 
Xu et al.: Prevalence of Overweight and Obesity among Chinese Adults: Role of Adiposity Indicators and Age

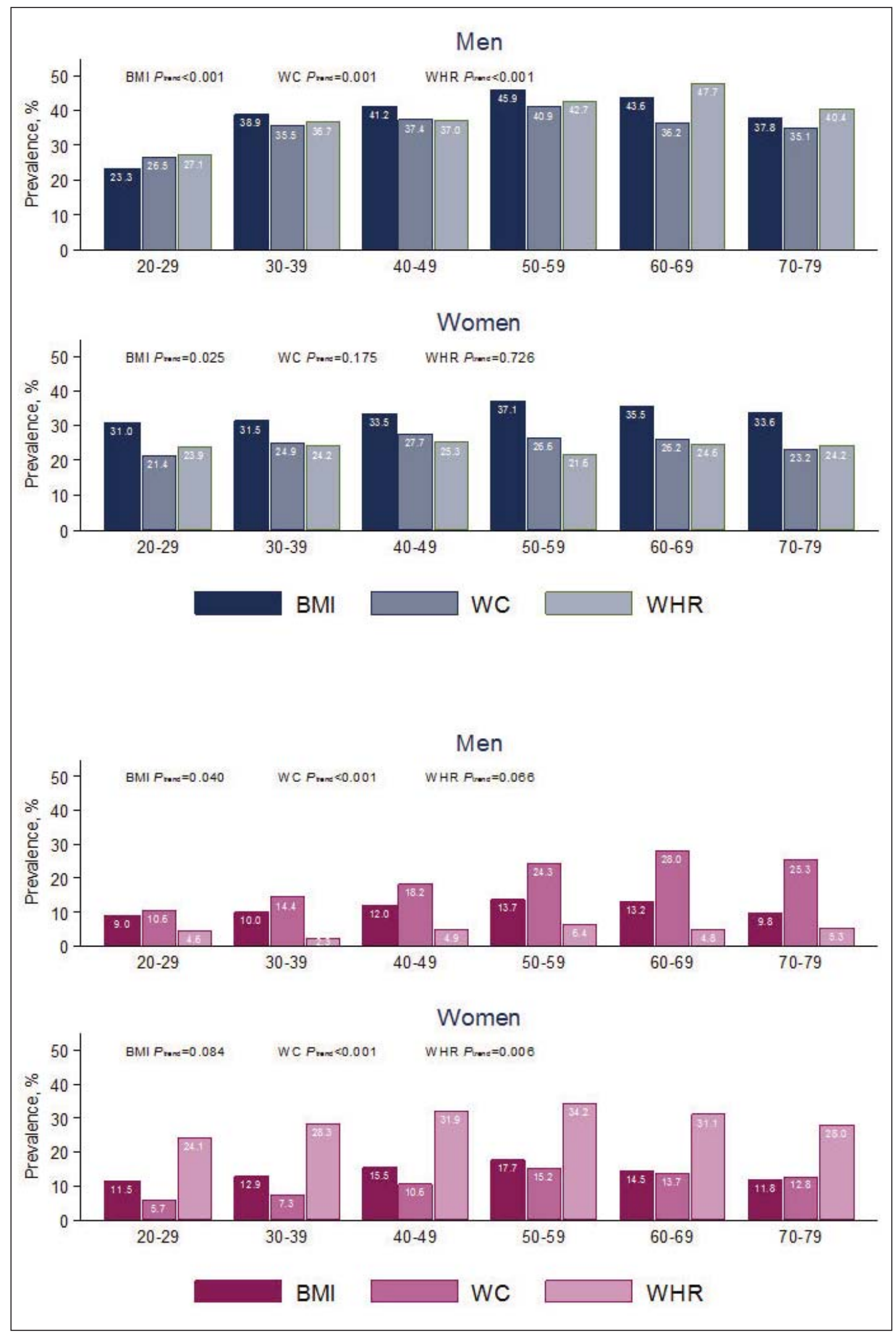

Fig. 3. The prevalence of overweight (A) and obesity (B) based on BMI, WC, and WHR with respect to age groups and sex. 


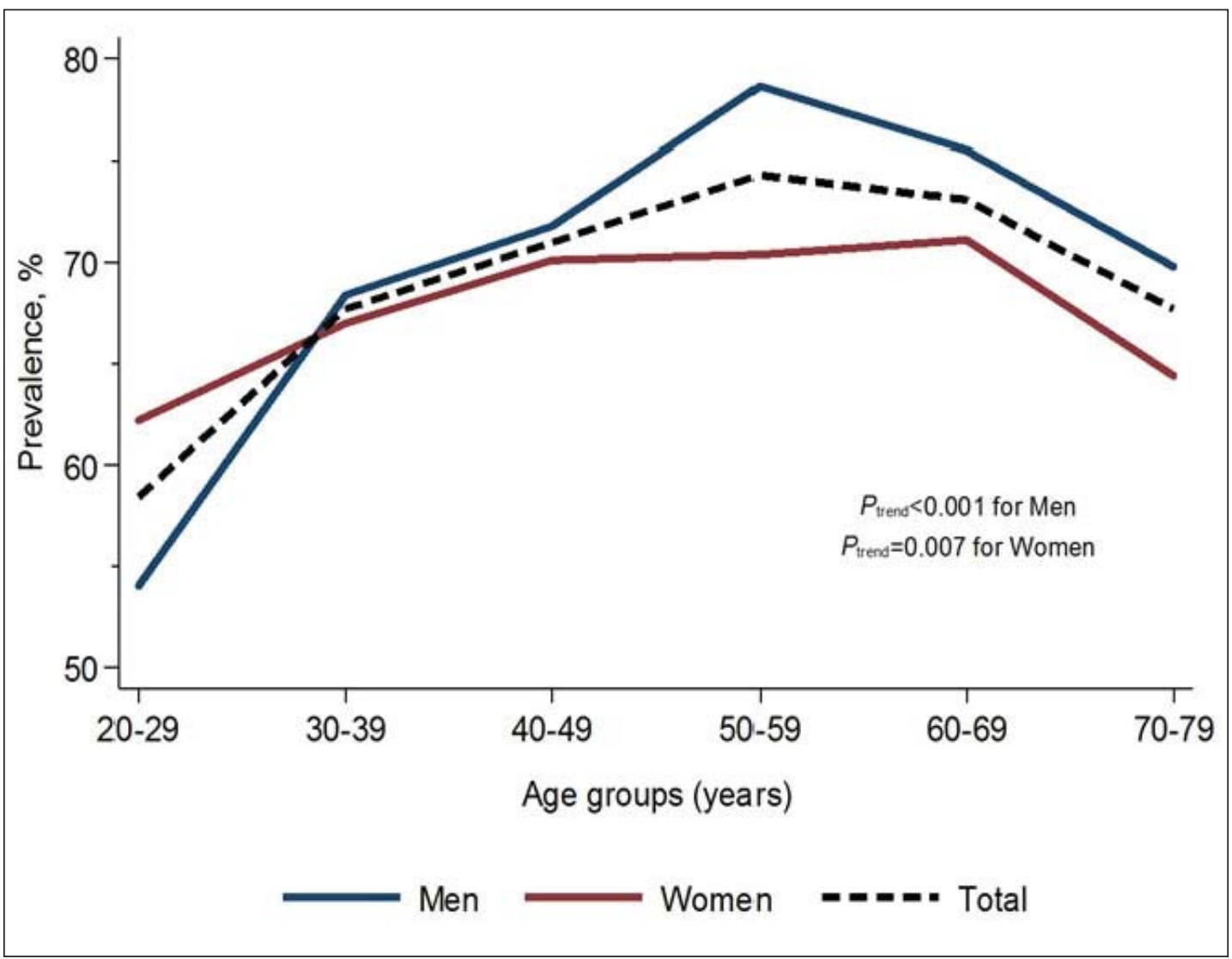

Fig. 4. Prevalence of high adiposity (overweight or obesity) defined by the combination of BMI, WC, and WHR by age and sex.

In logistic regression analysis, the odds of high adiposity defined by the three indicators showed an increase with age for people $<60$ years, but a decrease for people $\geq 60$ years. In people aged $<60$ years, female sex was associated with decreased odds of high adiposity when WC was used, but with increased odds when the calculation was based on WHR. In people $<60$ years, education ( $>9$ years) was related to increased odds of high adiposity defined by BMI, but not by WHR. In people $\geq 60$ years, cigarette smoking was related to decreased odds of high adiposity defined by BMI and WC. In contrast alcohol drinking was related to increased odds of high adiposity defined by WC in both age groups and by BMI in people $\geq 60$ years. The associations of hypertension and diabetes with high adiposity, defined by all the three indicators, were statistically significant, with WC showing the strongest correlation (table 3). There was no statistically significant association between physical inactivity and high adiposity in the present study.

\section{Discussion}

In this large population-based cross-sectional study, we found the following:

- The prevalence of overweight and obesity assessed by the combination of BMI, WC, and WHR was about $70 \%$, and increased with age till the age of 60 years and a decline thereafter. 
Xu et al.: Prevalence of Overweight and Obesity among Chinese Adults: Role of Adiposity Indicators and Age

Table 3. Multi-adjusted odd ratios (95\% confidence interval) for having high adiposity (overweight or obese) based on BMI, WC, and WHR, with demographic and lifestyle factors, hypertension and diabetes

\begin{tabular}{|c|c|c|c|c|c|c|}
\hline \multirow[t]{2}{*}{ Factors } & \multicolumn{6}{|l|}{ OR $(95 \% \mathrm{CI})^{*}$} \\
\hline & \multicolumn{2}{|l|}{ BMI } & \multicolumn{2}{|l|}{ WC } & \multicolumn{2}{|l|}{ WHR } \\
\hline Age, years & $1.02(1.01-1.02)$ & $0.97(0.94-0.99)$ & $1.02(1.01-1.02)$ & $0.97(0.95-1.00)$ & $1.01(1.00-1.01)$ & $0.97(0.95-1.00)$ \\
\hline Female & $0.92(0.81-1.06)$ & $0.95(0.75-1.21)$ & $0.48(0.42-0.55)$ & $0.39(0.30-0.50)$ & $1.78(1.55-2.04)$ & $1.25(0.99-1.59)$ \\
\hline Education(>9 years) & $1.15(1.02-1.29)$ & $1.26(1.00-1.59)$ & $0.92(0.81-1.04)$ & 1.07 (0.84-1.37) & $0.80(0.71-0.90)$ & $1.04(0.83-1.31)$ \\
\hline Cigarette smoking & $0.90(0.79-1.03)$ & $0.69(0.54-0.88)$ & $1.03(0.89-1.18)$ & $0.62(0.47-0.81)$ & $1.01(0.88-1.16)$ & $0.88(0.68-1.12)$ \\
\hline Alcohol drinking & $1.07(0.92-1.23)$ & $1.39(1.06-1.84)$ & $1.25(1.07-1.45)$ & $1.34(1.00-1.80)$ & $1.16(1.00-1.34)$ & $0.94(0.71-1.23)$ \\
\hline Physical inactivity & $1.01(0.91-1.18)$ & $1.05(0.94-1.15)$ & $1.05(0.87-1.44)$ & $1.02(0.90-1.09)$ & $1.04(0.92-1.16)$ & $1.05(0.95-1.17)$ \\
\hline Hypertension & $1.86(1.64-2.10)$ & $1.71(1.38-2.12)$ & $2.48(2.18-2.81)$ & $2.30(1.84-2.89)$ & $1.59(1.41-1.80)$ & $1.60(1.29-1.98)$ \\
\hline Diabetes & $1.60(1.30-1.96)$ & $1.91(1.43-2.57)$ & $3.58(2.85-4.51)$ & $5.17(3.64-7.33)$ & $2.39(1.93-2.95)$ & $2.66(1.95-3.62)$ \\
\hline
\end{tabular}

${ }^{*}$ The reference group are those with normal weight defined as BMI ranged between 18.5 and 23.9 , WC $<85$ in men and $<80$ in women, and WHR $<0.90$ in men and $<0.80$ in women, respectively.

- Most overweight people assessed by WC and WHR could also be identified by BMI, but not men $\geq 60$ years, while obesity by BMI may not cover a substantial proportion of obese people defined by WC in men and by WHR in women.

- The associations of hypertension and diabetes with high adiposity defined by WC were stronger than those when BMI and WHR were used for high adiposity definition.

China, with its rapid economic increase in the recent three decades, has undergone epidemiological and demographic transitions affecting its population's nutritional status and creating environments that contribute to increases in obesity prevalence, especially in the urban areas [21-23, 24]. The prevalence of obesity reported in the current study is considerably higher than that in a previous study on Chinese adults [4]. Based on the data from the China National Nutrition Survey, 3.3\% of the population aged 18 years or older was obese in 1992. In contrast, the prevalence of obesity (defined by BMI) in our study was $12.8 \%(11 \%$ in men and $14 \%$ in women), showing 3.9-fold rise over 13 years. The prevalence of obesity in our study is considerably lower than that in the USA (about 33\%) and the UK (31\%) [25], but comparable to that of most European countries (8.5-21\%) [26, 27].

Our study indicated significant differences in the prevalence of overweight and obesity assessed by the three anthropometric indicators BMI, WC, and WHR. There were differences in the mean values of BMI, WC, and WHR between men and women as shown from the MONICA study [28]. We also found that the means of the three indicators changed with age, and showed different patterns suggesting that these indicators may not be comparable across different age groups. The mean BMI was lower in young men than in young women, but had a more rapid rise in BMI in men $\geq 30$ years. The pattern of BMI change with age in our study is consistent with the results of other studies $[13,29]$.

WC provides an alternative measure for adiposity, which is well correlated with BMI, but appeared to be a better indicator of type 2 diabetes and hypertension [30]. Based on WC, 14\% of the population in the present study was defined as obese. Previous studies in western countries [13, 31, 32] have reported a higher prevalence of obesity using WC (24.4-59.9\%) than in our study. WHR has been suggested to be a better indicator of central adiposity [33]. The prevalence of obesity by WHR in our population raised almost $18 \%$. Interestingly, women showed a much higher prevalence of obesity by WHR (29.6\%) than men (4.6\%). These rates are quite similar to those reported from a study in the Cameroon adult population $(3.2 \%$ for men and $28.8 \%$ for women) [34]. Using the combination of the three indicators, our results 
Xu et al.: Prevalence of Overweight and Obesity among Chinese Adults: Role of Adiposity Indicators and Age

show that the prevalence of high adiposity increased till 60 years, but declined thereafter. Our study also shows that associations of high adiposity measured by WC with diabetes and hypertension were stronger than that of those measured by BMI or WHR, especially among people $\geq 60$ years. These results suggest that using different adiposity indicators may not only influence prevalence rates of high adiposity, but also its suitability for indicating vascular risk factors.

Few studies have shown the prevalence of overweight and obesity using BMI, WHR, and WC independently. The prevalence of obesity was $20.8 \%$ by BMI, $30.5 \%$ by WC, and $15.8 \%$ by WHR in an Australian population [35]. In a recent study in a Chinese adult population (with no WHR available), the prevalence rates of obesity were $12.2 \%$ by BMI and $27.1 \%$ by WC [36], being similar to our results. However, the prevalence of overweight and obesity using combined indicators has not been reported so far. We found that the prevalence of overweight and obesity assessed by the combination of BMI, WC, and WHR was about 70\%, and increased with age till the age of 60 years and declined thereafter.

The main strength of our study is the large population-based representative sample of the adult population in Tianjin, with comprehensive indicators on adiposity among all participants. However, some limitations need to be pointed out. First, the temporality of the given associations is unclear because of the cross-sectional design of the current study, thus the adiposity measurements cannot be used to predict the risk of incident diabetes and hypertension. Second, individuals with severe obesity or long-standing chronic disease might have refused to participate in this study because of their unhealthy condition. This might have led to underestimation of the prevalence of obesity and its relation to diabetes and hypertension. Third, it is possible that individuals with normal weight might be more interested in participation than those without the condition. However, the participation rate was high (95\%), and the prevalence of overweight and obesity in this study is comparable with those in previous reports. Thus, the participation bias might not be substantial. Finally, information on several obesity-related complications, such as cerebral vascular disease and coronary heart disease, was not available. But, we had comprehensive clinical assessment for diabetes and hypertension, which might be considered proxies for vascular disorders.

In conclusion, our study provides evidence that the prevalence of overweight and obesity assessed by the combination of BMI, WC, and WHR is very high among the Chinese adults, and increased with age till the age of 60 years and declined thereafter. When BMI was used to define overweight and obesity, a substantial proportion of obese and overweight people identified by WC and WHR may not be covered. High adiposity defined by WC seems to be a better indicator for hypertension and diabetes than that defined by BMI or WHR, especially in people $\geq 60$ years. Our findings implicated that different adiposity measurements and age should be considered when assessing overweight and obesity. Large-scale population-based longitudinal studies addressing the role of age and different indices for adiposity are warranted.

\section{Acknowledgements}

The work was supported by a grant (30471490 to XQ) from the National Natural Science Foundation of China and grant from the Swedish Council for Working Life and Social Research (FAS 0022 to WX), the Board of Research, Karolinska Institute, and partly from the private foundations (Gamla Tjänarinnor Foundation, Diabetesfonden and the Bertil Stohnes).

\section{Disclosure Statement}

The authors declare no conflict of interest. 
Xu et al.: Prevalence of Overweight and Obesity among Chinese Adults: Role of Adiposity Indicators and Age

\section{References}

1 alence of overweight and obesity in children and adults during 1980-2013: a systematic analysis for the global burden of disease study 2013. Lancet 2014;384:766-781.

3 Rizzuto D, Fratiglioni L: Lifestyle factors related to mortality and survival: a mini-review. Gerontology 2014; 60:327-335.

4 Wang Y, Mi J, Shan XY, Wang QJ, Ge KY: Is China facing an obesity epidemic and the consequences? The trends in obesity and chronic disease in China. Int J Obes 2007;31:177-188.

5 Li X, Jiang Y, Hu N, Li Y, Zhang M, Huang Z, Zhao W: Prevalence and characteristic of overweight and obesity among adults in China, 2010 (in Chinese). Zhonghua Yu Fang Yi Xue Za Zhi 2012;46:683-686.

6 Gallagher D, Visser M, Sepulveda D, Pierson RN, Harris T, Heymsfield SB: How useful is body mass index for comparison of body fatness across age, sex, and ethnic groups? Am J Epidemiol 1996;143:228-239.

7 Smalley KJ, Knerr AN, Kendrick ZV, Colliver JA, Owen OE: Reassessment of body mass indices. Am J Clin Nutr 1990;52:405-408.

8 Pouliot MC, Despres JP, Lemieux S, Moorjani S, Bouchard C, Tremblay A, Nadeau A, Lupien PJ: Waist circumference and abdominal sagittal diameter: best simple anthropometric indexes of abdominal visceral adipose tissue accumulation and related cardiovascular risk in men and women. Am J Cardiol 1994;73:460-468.

9 Despres JP, Prud'homme D, Pouliot MC, Tremblay A, Bouchard C: Estimation of deep abdominal adipose-tissue accumulation from simple anthropometric measurements in men. Am J Clin Nutr 1991;54:471-477.

10 Browning LM, Hsieh SD, Ashwell M: A systematic review of waist-to-height ratio as a screening tool for the prediction of cardiovascular disease and diabetes: 0.5 could be a suitable global boundary value. Nutr Res Rev 2010;23:247-269..

11 Chang ST, Chu CM, Lin PC, Pan KL, Cheng HW, Yang TY, Chung CM, Hsu JT: Different degrees of overweight: anthropometric indices in patients with coronary heart disease. Acta Cardiol 2009;64:291-296.

12 Hajian-Tilaki KO, Heidari B: Prevalence of obesity, central obesity and the associated factors in urban population aged 20-70 years, in the north of Iran: a population-based study and regression approach. Obes Rev 2007;8:3-10.

13 Cameron AJ, Welborn TA, Zimmet PZ, Dunstan DW, Owen N, Salmon J, Dalton M, Jolley D, Shaw JE: Overweight and obesity in Australia: The 1999-2000 Australian Diabetes, Obesity and Lifestyle study (AUSDIAB). MedJ Aust 2003;178:427-432.

14 Baumgartner RN, Heymsfield SB, Roche AF: Human body composition and the epidemiology of chronic disease. Obes Res 1995;3:73-95.

15 Kopelman PG, Caterson ID, Dietz WH: Clinical Obesity in Adults and Children, 3rd ed. Hoboken, Wiley Blackwell, 2009.

16 Ho RC, Niti M, Kua EH, Ng TP: Body mass index, waist circumference, waist-hip ratio and depressive symptoms in Chinese elderly: a population-based study. Int J Geriatr Psychiatry 2008;23:401-408.

$17 \mathrm{Xu} \mathrm{W}, \mathrm{Xu} Z$ Z, Jia J, Xie Y, Wang H-X, Qi X: Detection of prediabetes and undiagnosed type 2 diabetes: A large population-based study. Can J Diabetes 2012;36:108-113.

18 Qi X, Sun J, Wang J, Wang PP, Xu Z, Murphy M, Jia J, Xie Y, Xu W: Prevalence and correlates of latent autoimmune diabetes in adults in Tianjin, China: a population based cross-sectional study. Diabetes Care 2011;34:66-70.

19 Alberti KG, Zimmet PZ: Definition, diagnosis and classification of diabetes mellitus and its complications. Part 1: diagnosis and classification of diabetes mellitus. Provisional report of a WHO consultation. Diabet Med 1998; 15:539-553.

20 Zhou BF: Predictive values of body mass index and waist circumference for risk factors of certain related diseases in Chinese adults: Study on optimal cut-off points of body mass index and waist circumference in Chinese adults. Asia Pac J Clin Nutr 2002;11(suppl 8):S685-693.

21 Wang H, Du S, Zhai F, Popkin BM: Trends in the distribution of body mass index among Chinese adults, aged 20-45 years (1989-2000). Int J Obes 2007;31:272-278.

22 Wu Y: Overweight and obesity in China. BMJ 2006;333:362-363.

23 Shen J, Goyal A, Sperling L: The emerging epidemic of obesity, diabetes, and the metabolic syndrome in China. Cardiol Res Pract 2012;2012:178675.

24 Xu Y, Wang L, He J, Bi Y, Li M, Wang T, Wang L, Jiang Y, Dai M, Lu J, Xu M, Li Y, Hu N, Li J, Mi S, Chen CS, Li G, Mu Y, Zhao J, Kong L, Chen J, Lai S, Wang W, Zhao W, Ning G; China Noncommunicable Disease Surveillance Group: Prevalence and control of diabetes in Chinese adults. JAMA 2013;310:948-959.

25 Zaninotto P, Head J, Stamatakis E, Wardle H, Mindell J: Trends in obesity among adults in England from 1993 to 2004 by age and social class and projections of prevalence to 2012. J Epidemiol Commun Health 2009;63: 140-146.

26 Berghofer A, Pischon T, Reinhold T, Apovian CM, Sharma AM, Willich SN: Obesity prevalence from European perspective: a systematic review. BMC Public Health 2008;8:200.

27 Gallus S, Odone A, Lugo A, Bosetti C, Colombo P, Zuccaro P, La Vecchia C: Overweight and obesity prevalence and determinants in Italy: an update to 2010. Eur J Nutr 2013;52:677-685.

28 Molarius A, Seidell J, Sans S, Tuomilehto J, Kuulasmaa K: Waist and hip circumferences, and waist-hip ratio in 19 populations of the WHO MONICA Project. Int J Obes Relat Metab Disord 1999;23:116-125. 
Xu et al.: Prevalence of Overweight and Obesity among Chinese Adults: Role of Adiposity Indicators and Age

29 Flegal KM, Carroll MD, Ogden CL, Johnson CL: Prevalence and trends in obesity among US adults, 1999-2000. JAMA 2002;288:1723-1727.

30 Xin Z, Liu C, Niu W-Y, Feng J-P, Zhao L, Ma Y-H, Hua L, Yang J-K: Identifying obesity indicators which best correlate with type 2 diabetes in a Chinese population. BMC Public Health 2012;12:732.

31 Howel D: Trends in the prevalence of abdominal obesity and overweight in English adults (1993-2008). Obesity (Silver Spring) 2012;20:1750-1752.

32 Garcia-Alvarez A, Serra-Majem L, Ribas-Barba L, Castell C, Foz M, Uauy R, Plasencia A, Salleras L: Obesity and overweight trends in Catalonia, Spain (1992-2003): Gender and socio-economic determinants. Pub Health Nutr 2007;10:1368-1378.

33 Ashwell M, Hsieh SD: Six reasons why the waist-to-height ratio is a rapid and effective global indicator for health risks of obesity and how its use could simplify the international public health message on obesity. Int J Food Sci Nutr 2005;56:303-307.

34 Kamadjeu RM, Edwards R, Atanga JS, Kiawi EC, Unwin N, Mbanya JC: Anthropometry measures and prevalence of obesity in the urban adult population of Cameroon: an update from the Cameroon burden of diabetes baseline survey. BMC Pub Health 2006;6:228.

35 Dalton M, Cameron AJ, Zimmet PZ, Shaw JE, Jolley D, Dunstan DW, Welborn TA; AusDiab Steering Committee: Waist circumference, waist-hip ratio and body mass index and their correlation with cardiovascular disease risk factors in Australian adults. J Intern Med 2003;254:555-563.

36 Hou X, Lu J, Weng J, Ji L, Shan Z, Liu J, Tian H, Ji Q, Zhu D, Ge J, Lin L, Chen L, Guo X, Zhao Z, Li Q, Zhou Z, Shan G, Yang Z, Yang W, Jia W; China National Diabetes and Metabolic Disorders Study Group: Impact of waist circumference and body mass index on risk of cardiometabolic disorder and cardiovascular disease in Chinese adults: A national diabetes and metabolic disorders survey. PloS One 2013;8:e57319. 